\title{
Aortic Valve
}

National Cancer Institute

\section{Source}

National Cancer Institute. Aortic Valve. NCI Thesaurus. Code C12670.

A valve that is located between and controls the flow of blood from the left ventricle of the heart and the aorta. 